\title{
Spermiogenesis and Taxonomical Values of Sperm Ultrastructures in Male Crassostrea ariakensis (Fujita \& Wakiya, 1929) (Pteroirmorphia: Ostreidae) in the Estuary of the Seomjin River, Korea
}

\author{
Pal Won Son ${ }^{1}$, Jae Seung Chung ${ }^{2}$, Jin Hee $\mathrm{Kim}^{3}$, Sung Han $\mathrm{Kim}^{4}$ and $^{\dagger}$ Ee-Yung Chung ${ }^{5}$ \\ ${ }^{1}$ Korea Marine Ecology Institute, Busun 612-020, Korea \\ ${ }^{2}$ Department of Urology, College of Medicine, Inje University, Busan 614-735, Korea \\ ${ }^{3}$ Korea Ocean \& Fisheries Institute, Busan 608-810, Korea \\ ${ }^{4}$ Department of Aquaculture and Aquatic Sciences, Kunsan National University, Gunsan 573-701, Korea \\ ${ }^{5}$ Department of Marine Biotechnology, Kunsan National University, Gunsan 573-701, Korea
}

\begin{abstract}
Characteristics of the developmental stages of spermatids during spermiogenesis and phylogenetic classicfication of the species using sperm ultrastructures in male Crassostrea ariakensis were investigated by transmission electron microscope observations. The morphology of the spermatozoon of this species has a primitive type and is similar to those of Ostreidae. Ultrastructures of mature sperms are composed of broad, modified cap-shaped acrosomal vesicle and an axial rod in subacrosomal materials on an oval nucleus, four spherical mitochondria in the sperm midpiece, and satellite fibres which appear near the distal centriole. The axoneme of the sperm tail shows a 9+2 structure. Accordingly, the ultrastructural characteristics of mature sperm of $C$. ariakensis resemble to those of other investigated ostreids in Ostreidae in the subclass Pteriomorphia. In this study, particularly, two transverse bands (stripes) appear at the anterior region of the acrosomal vesicle of this species, unlike two or three transverse bands (stripes) in C. gigas. It is assumed that differences in this acrosomal substructure are associated with the inability of fertilization between the genus Crassostrea and other genus species in Ostreidae. Therefore, we can use sperm ultrastructures and morphologies in the resolution of taxonomic relationships within the Ostreidae in the subclass Pteriomorphia. These spermatozoa, which contain several ultrastructures such as acrosomal vesicle, an axial rod in the sperm head part and four mitochondria and satellite fibres in the sperm midpiece, belong to the family Ostreidae in the subclass Pteriomorphia.
\end{abstract}

Key words : Crassostrea ariakensis, Spermiogenesis, Germ cell, Sperm ultrastructure

\section{INTRODUCTION}

The oyster, C. ariakensis (Fujita \& Wakiya, 1929) is distributed along the estuary of the Seomjin River and Wando, Jeollanam-do, Korea. More specifically, in Korea, this species is mainly found at the mud including silty and clay around the rocks in the intertidal and subtidal zones, However, in connection with the recent sharp reduction in its standing stock by reckless overcatching and environmental pollutions, it has been noted as a regional target organism that should be managed for the conservation of natural living resources. Particularly, studies on repro-

\footnotetext{
Manuscript received 20 August 2014, Received in revised form 27 August 2014, Accepted 4 September 2014

${ }^{\dagger}$ Corresponding Author : Ee-Yung Chung, Department of Marine Biotechnology, Kunsan National University, Gunsan 573-701, Korea. Tel.: +82-63-4691832, E-mail: eychung@kunsan.ac.kr

This is an Open Access article distributed under the terms of the Creative Commons Attribution Non-Commercial License (http:// creativecommons.org/licenses/by-nc/3.0) which permits unrestricted non-commercial use, distribution, and reproduction in any medium, provided the original work is properly cited.
} 
ductive stratege of this species are supposed to be one of the most important tasks for the propagation of natural resources.

To date, ten oyster species in Ostreidae in the subclass Pteriomorphia were reported in Korea. Regarding reproduction of $C$. ariakensis, there are only one report such as spermiogenesis of spermatids and the ultrastructures of spermatozoa (Kim, 2001). Recently, sperm ultrastructures have been used as a tool in assessing taxonomic problems and phylogenetic relationships in the Metazoa through the use of spermiocladistic analysis (Jamiesen, 1987, 1991). Recently, sperm ultrastructure has been used successfully as an aid in the examination of the phylogeny of bivalvia (Popham, 1979; Bernard \& Hodgson, 1985; Healy, 1983; 1989; Healy \& Lester, 1991). Daniels et al. (1971) suggested that comparative ultrastructure of oyster spermatozoa might be taxonomically useful because morphological differences between taxa could be found.

Although spermatogenesis and mature sperm ultrastructures have been described in some Ostreidae species in the subclass Pteriomorphia (Daniels et al., 1971; Popham, 1974, 1979; Healy and Lester, 1991; Sousa and Oliveria, 1994; Eckelbarger and Davis, 1996; Kim, 2001; Kim et al., 2010), little information is available on spermiogenesis and mature sperm ultrastructures associated with taxonomic problems and phylogenetic relationships of the oyster in the Seomjin River, C. ariakensis.

Above all, it is very important to clarify some differrences between ultrastructures of mature spermatozoon associated with the nucleus, acrosomal vesicle and the number of mitochondria. In addition, appearance of an axial rod (substructure) and the satellite fibers should be confirmed. The pupose of the present study is to clarify the some ultrastuctral charateristics of spermatids during spermiogenesis, and also to confirm phylogenetic relationships of the oysters using the sperm ultrastructures of $C$. ariakensis and other closely related oyster species within
Ostreidae in the subclass Pteriormorphia. Therefore, it needs to clarify the appearance of the number of transverse bands (as the substructure) on the acrosomal vesicles of mature sperm of this species.

\section{MATERIALS AND METHODS}

\section{Sampling}

The specimens of C. ariakensis, were collected monthly in the intertidal and subtidal zones at the estuary of the Seomjin River, Chollanam-do, Korea, for one year from January to December, 2007. A total of 144 male oysters were used for transmission electron microscope observations.

\section{Transmission electron microscope observation}

For transmission electron microscope observations, excised pieces of the gonads were cut into small pieces and fixed immediately in $2.5 \%$ paraformaldehydeglutaraldehyde in $0.1 \mathrm{M}$ phosphate buffer solution $(\mathrm{pH}$ 7.4) for 2 hours at $4^{\circ} \mathrm{C}$. After prefixation, the specimens were washed several times in the buffer solution and then postfixed in a $1 \%$ osmium tetroxide solution in $0.2 \mathrm{M}$ phosphate buffer $(\mathrm{pH}$ 7.4) for 1 hour at $4^{\circ} \mathrm{C}$. Specimens then were dehydrated in increasing concentrations of ethanol, cleared in propylene oxide and embedded in an Epon-Araldite mixture. Ultrathin sections of Epon-embedded specimens were cut with glass knives on a Sorvall MT-2 microtome and LKB ultramicrotome at a thickness of about $80-100 \mathrm{~nm}$. Tissue sections were mounted on collodion-coated copper grids, doubly stained with uranyl acetate followed by lead citrate, and observed with a JEM $100 \mathrm{CX}-\Pi$ (80-KV) electron microscope.

\section{RESULTS}

1. Ultrastructural changes in spermatids during spermiogenesis and characteristics of sperm ultrastructures 
The general ultrastructures of the testis of $C$. ariakensis is similar to those of other bivalve species. The processes of spermiogenesis of this species appear to be similar to species of other families in the subclass Pteriomorphia. However, compared with those of the families in the subclass Pteriomorphia, there are some differences in sperm ultrastructures: a few transverse bands on the anterior region (top) of the acrosomal vesicle and an axial rod, which is embedded in a coasely granular matrix (subacrosomal materials), is detected in the spermatid and spermatozoon stages.

\section{1) Spermatid stage}

Spermiogenesis occurs in the spermatids. For convenience, spermatid stage could be classified arbitrarily into two stages: the early and late stages. In the early stage of spermiogenesis, the nuclei (about 2.7-2.8 $\mu \mathrm{m}$ diameter) of spermatids (3.6-4.1 $\mu \mathrm{m})$ is spherical and occupies the center of the cell. contain heterochromatin materials in the nucleus. During spermiogenesis, the external morphology of the spermatid nucleus gradually changes during the differentiation of the spermatids. Consequently, the morphologies of the spermatid nuclei are laterally wided, and one or a few granules were formed by the Golgi complex in the cytoplasm of the spermatid (Fig. 1A). And a few granules formed a large proacrosomal vesicle (Fig. 1B), a proacrosomal vesicle migrated to anterior end of the spermatid (Fig. 1C), where they coalesce to form a single electron-dense proacrosomal vesicle (Fig. 1D). A single acrosomal vesicle locates at the anerior pole of the spermatids (Fig. 1E).

In the late stage of spermiogenesis, the acrosomal vesicle is initially oval in shape but gradually assumes modified caplike form with a slightly pointed anterior nuclear fossa and a sharply invaginated posterior nuclear fossa. At this time, the acrosomal vesicle and an extensive deposit of subacrosomal (extravesicular) materials. At this time, the satellite fibres appeared near the distal centriole under the nucleus and spherical mitochondria (Fig. 1F). Two components of the acrosomal vesicle can be recognized: the processes of acrosomal vesicle formation are very complex. The acrosomal vesicle is membrane bound, consequently, become modified cap-like form by various morphorphological changes. The acrosomal vesicle is gradually changed to oval in shape and the anterior nuclear fossa of laterally wide nucleus is deeply invaginated, and then the space is occupied by subacrosomal materials. Anteriorly oval nucleus is deeply invaginated, however, posterior nuclear fossa is not deeper than that of anterior nuclear fossa. A longitudinal flagellum is connected to the distal centriole near two large sherical mitochondria in the sperm midpiece. The satellite fiber is located near the distal centriole under the nucleus and spherical mitochondria (Fig. 1G).

\section{2) Spermatozoon stage}

The morphology of the spermatozoon of C. ariakensis has a primitive type. And the head part of the sperm is about $2.02 \mu \mathrm{m}$ long, and the sperm is approximately $48-50$ $\mu \mathrm{m}$ long including a wider nucleus $(1.65 \mu \mathrm{m}$ width) than the length of the nucleus $(0.94 \mu \mathrm{m}$ long $)$, and also a finely granular subacrosomal materials are present in the anterior invagination region (anterior nuclea fossa) of the nucleus. The acrosome is modified cap-like form. Two centrioles (proximal and distal centrioles) and large two spherical mitochondria are found in the midpiece of the sperm. The proximal centriole lies at $90^{\circ}$ to the sperm longitudinal axis or the distal centriole near the basal invagination of the nucleus (posterior nuclear fossa). The distal centrile lies parallel to the sperm longitudinal axis and forms the point of origin of flagellar axoneme. Two transverse banding appeared at the anterior region of the acrosomal vesicle. An acrosomal vesicle $(0.64 \mu \mathrm{m}$ long and $0.27 \mu \mathrm{m}$ width) is composed of electron dense opaque materials) on the nucleus is composed of the acrosomal vesicle (being composed of the modified cap-shaped basal rings) and 

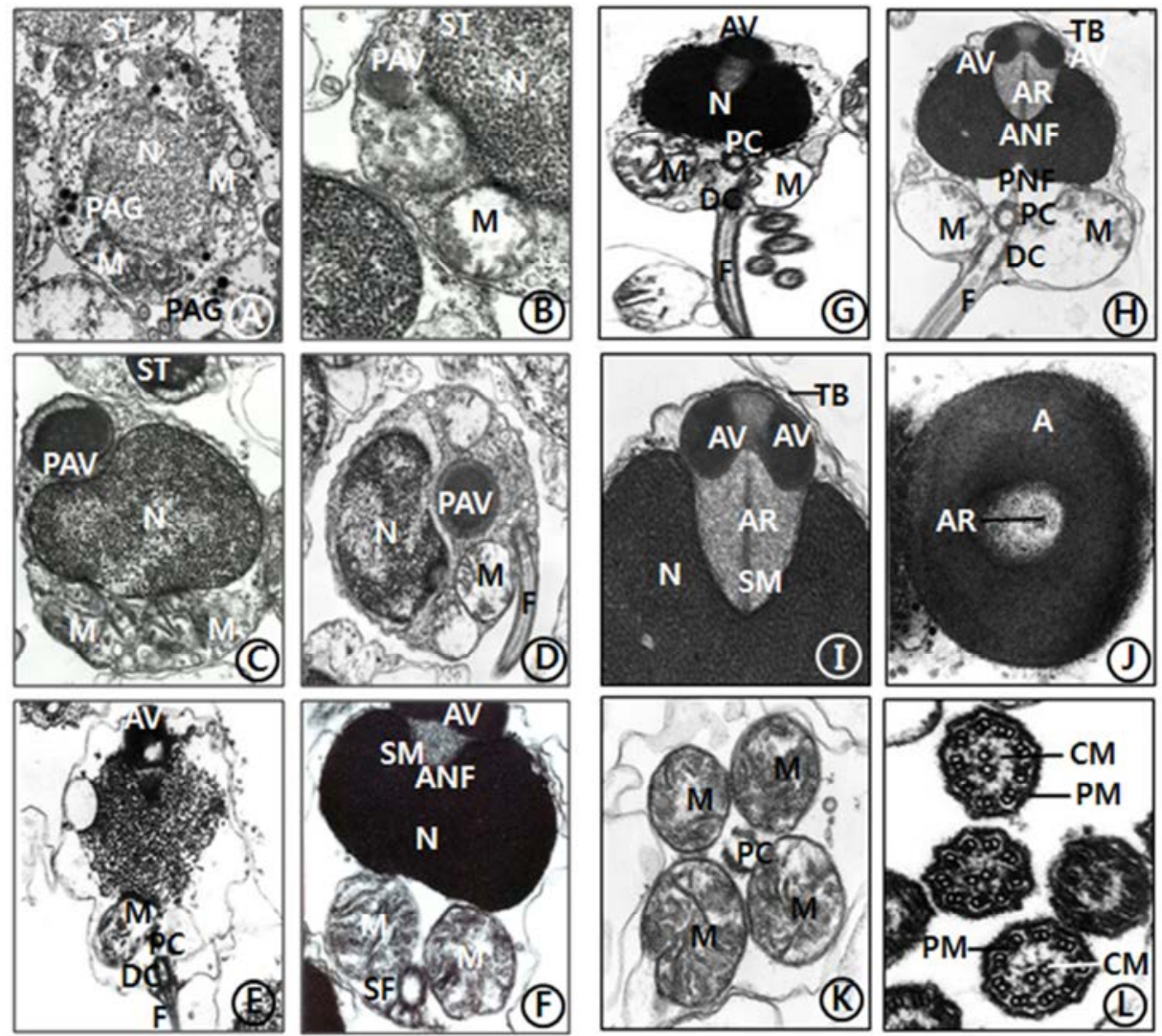

Fig. 1. Transmission electron micrographs of spermiogenesis and mature spermatozoon in male Crassostrea ariakensis (AL). A, A spermatid (ST) in the early stage of spermiogenesis. Note several proacrosomal granules (PAG) just before the nucleus $(\mathrm{N})$; B, C, The processes of the formation of the proacrosomal vesicles (PAV) of spermatids (ST). Note proacrosomal vesicles (PAV) just before the nucleus $(\mathrm{N})$ and two spherical mitochondria (M) in the midpiece of sperm; D, The middle stage of spermiogenesis, formations of proacrosomal vesicle (PAV), the midpiece of sperm and a flagellum. Note proacrosomal vesicle (PAV) on the nucleus (N) and mitochondria (M) and a flagellum (F); E, The formations of the acrosomal vesicle (AV) and the sperm midpiece. Note the acrosomal vesicle (AV), proximal centriole (PC), distal centriole (DC) surrounded with spherical mitochondria (M), and a flagellum (F); F, A spermatid in the late stage of spermiogenesis. Note appearance of the acrosomal vesicle, subacrosomal materials (SM) in the invagination region of the nucleus $(\mathrm{N})$ and formation of the sperm midpiece showing a satellite fibre (SF) near the distal centriole and spherical mitochondria (M); G, A spermatid in the late stage of spermiogenesis. Note an acrosomal vesicle (AV), an axial rod (AR) in the subacrosomal materials (SM) on the nucleus (N) and the proximal centriole (PC) and distal centrioles (DC) surrounded with mitochondria (M) near the satelite fibre (SF) in the sperm midpiece and a flagellum (F); H, A completed spermatozoon. Note transverse bandings (TB) on the anterior part of acrosomal vesicle (AV), an axial rod (AR); I, Completed acrosomal vesicle (AV) and the appearance of the axial rod and sperm midpiece. Note two (or three) transverse bandings (TB) on the aterior part of the acrosomal vesicle and an axial rod in the subacrosomal materials between the acrosomal vesicle (AV) and the nucleus $(\mathrm{N})$, proximal centriole (PC) and distal centriole (DC) and flagellum (F); J. Cross sectioned acrosome (A) and nucleus. Note the acrosome (A) and an axial rod (AR) in the subacrosomal granular materials; $\mathrm{K}$, Cross sectioned sperm midpiece. Note the proximal centriole (PC) surrounded with four spherical mitochondria (M); L, Cross sectioned flagella of sperms. Note an axoneme showing a 9+2 structure containing a pair of single doublet central microtubles (CM) and nine pairs of of peripheral microtubles (PM). 
subacrosomal materials which comprises an axial rod embedded in a coasely granular matrix. In particular, an axial rod, which is embedded in a coasely granular matrix (subacrosomal materials), is found between the acrosomal vesicle and the nucleus (Figs. 1H, 1I, 1J), as have seen in most species of Ostreidae.

In this stage, an acrosomal vesicle shows high electron dense opaque at the acrosomal membrane. In particular, two transverse bands (stripes) are present in the anterior region of acrosomal vesicle. At this time, two centrioles (proximal centriole and distal centriole) and two spherical mitochondria are located in the midpiece of the sperm. A long flagellum, which is occurred from the distal centriole, is located in the tail part of the sperm (Fig. 1H), as seen in C. gigas (Ostreidae) of the subclass Pteriomorphia.

Anteriorly oval nucleus $(0.94 \mu \mathrm{m}$ long and $1.65 \mu \mathrm{m}$ width) is deeply invaginated, and then the space is occupied by subacrosomal materials. Posteriorly, the nuclear contents are highly electron dense and granular in texture. In the cross sectioned acrosomal vesicle, an axial rod is present in the subacrosomal granular materials (Figs. 1I, 1J). Posterior to the nucleus is the midpiece. This region consists of four spherical mitochondria surrounding a pair of triplet substructure centrioles. The cristae of each mitochondrion are randomly arranged (Fig. 1K). A flagellum is composed of a $9+2$ substructure axoneme enclosed by the plasma membrane: that is, nine peripheral doublets (microtubules) surrounding a central pair microtubles (Fig. 1L and enclosed by the plasma membrane and measures approximately 42 $45 \mu \mathrm{m}$.

\section{DISCUSSION}

\section{Taxonomical values of sperm morphologies and ultrastructures}

Commonly, the morphology of the spermatozoon of bivalve species has a primitive type and is similar to those of other bivalves. In genal, the sizes of the sperm nuclei of bivalves prove unuseful in taxonomic analysis, because the morphological characteristics of sperm nuclei are irregular and vary among the species in a family (Healy, 1995; Kim et al., 2010).

Early investigations of bivalve sperm ultrastructure demonstrated the taxonomic value of comparative studies (Galtsoff \& Phillpott, 1960; Franzen, 1956; Popham, 1979), and such studies are widely used in taxonomic analyses (Hodgson \& Bernard, 1986; Healy, 1988, 1995, 1996). The primitive sperm show sufficient structural variability that they are useful in taxonomic studies (Kim et al., 2010). In general, morphology of ostreid sperm shows broad, modified cap like acrosome, extensive subacrosomal deposit materials (the appearance of an axial rod), oval nucleus, four pericentriolar mitochondria (Healy \& Lester, 1991; Kim et al., 2010).

In this study, as seen in the morphology of spermatozoon of $C$. gigas, mature spermatozoa of $C$. ariakensis consist of broad, modified cap-shaped acrosomal vesicle, an axial rod embedded in a granular matrix (subacrosomal materials), an oval nucleus showing deeply invaginated anteriorly, two triplet substructure centrioles surrounded by four spherical mitochondria.

Results of the present study support the sugestion of Daniels et al. (1971) that sperm ultrastructure may be of taxonomic use in the Ostreidae. Therefore, compared with most structures and morphologies, spermatozoa of $C$. ariakensis closely resemble those of other investigated ostreids (Daniels et al., 1971; Osanai \& Kyozuka, 1982; Healy \& Lester, 1991).

In this study, the acrosomal contents have a relatively uniform electron density. In case of Ostreidae species unlikely other family of bivales, the nucleus of the spermatid become wider than long, and a finely granular subacrosomal materials are present in the anterior invagination region of the nucleus. It is one of special characteristics of spermatozoa 


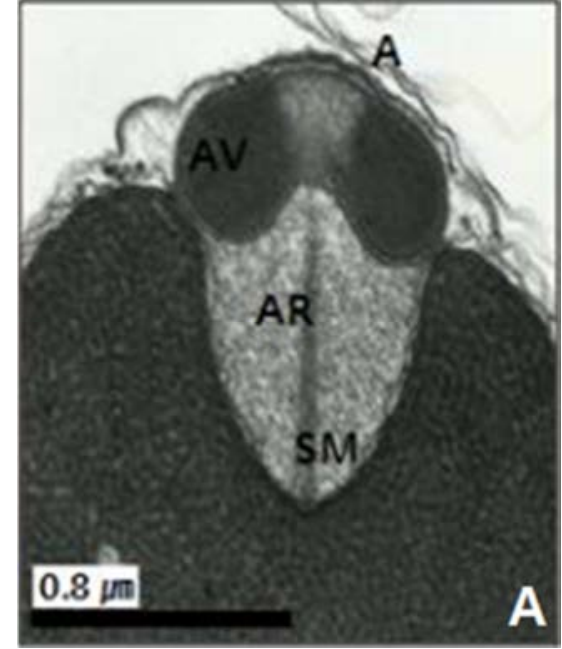

Fig. 2A. Electron photo- micrographs of the sperm ultrastructures of Crassostrea ariakensis in Ostreidae in the subclass Pteriomorphia.

The number of transverse bands (stripes) on the anterior region of right and left basal rings of the acrosomal vesicle: Two transverse bands (stripes).

Appearance of the axial rod (AR): exists in subacrosomal materials (SM) in the anterior nuclear invagination on the sperm nucleus $(\mathrm{N})$ in Ostreidae.

Appearance of the satellite fibres: exists near the distal centriole and mitochondria in Ostreidae. Therefire, it belongs to the subclass Pteriomorphia. (Present, 2014)

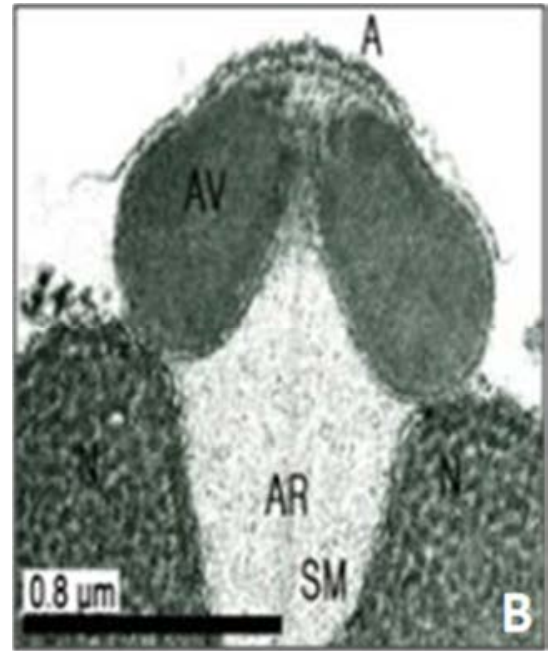

Fig. 2B. Electron photo- micrographs of the sperm ultrastructures of Crassostrea nipponica in Ostreidae in the subclass Pteriomorphia.

The number of transverse bands (stripes) on the anterior region of right and left basal rings of the acrosomal vesicle: Two transverse bands (stripes).

Appearance of the axial rod (AR): Existed in subacrosomal materials (SM) in the anterior nuclear invagination on the sperm nucleus (N) in Ostreidae.

Appearance of the satellite fibres: exists near the distal centriole and mitochondria in Ostreidae. Therefore, it belongs to the subclass Pteriomorphia. (Kim, 2001)

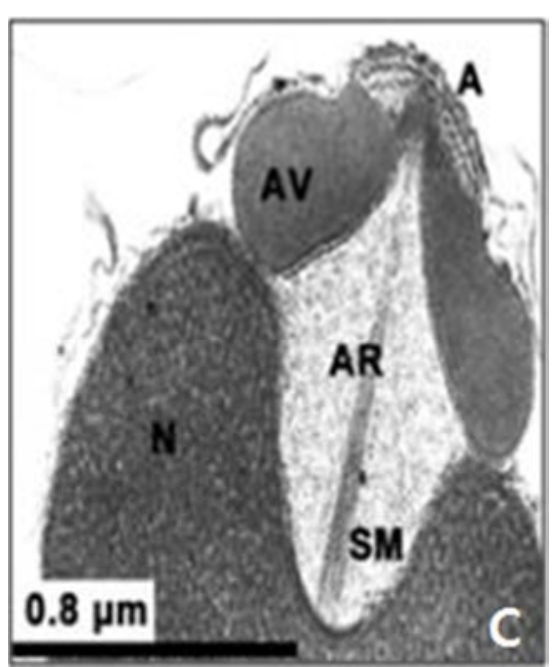

Fig. 2C. Electron photo- micrographs of the sperm ultrastructures of Crassostrea gigas in Ostreidae in the subclass Pteriomorphia.

The number of transverse bands (stripes) on the anterior region of right and left basal rings of the acrosomal vesicle: Two or three transverse bands.

Appearance of the axial rod (AR): Existed in subacrosomal materials (SM) in the anterior nuclear invagination on the sperm nucleus $(\mathrm{N})$ in Ostreidae.

Appearance of the satellite fibres: exists near the distal centriole and mitochondria in Ostreidae. Therefore, It belongs to the subclass Pteriomorphia. (Kim et al., 2010) of Ostreidae species.

Regarding a central filamentous axial rod, in this study, the subacrosomal matterial contains a central filamentous axial rod composed of anterio-posterior-oriented filaments as seen in the family Ostreidae species of the subclass Pteriomorphia.

The taxonomic value of sperm morpholgy at the level of species or genus in the Ostreidae will be determined only through a broad, comparative study. In this study, the anterior region of the acrosomal vesicle consisted of alternating electron dense and electron lucent bands. In particular, the acrosomal membrane in the acrosomal vesicle exhibited high electron dense opaque region. while two or three bands are present in the anterior region of the acrosomal vesicle which was exhibited electron-lucents whorls. A similar whorled substructure might also occur in acrosomes of $C$. virginica, through the micrograph presented by Daniels et al. (1971) were not detailed enough to 
confirm this. In this study, two transverse bandings (stripes) appeared in C. ariakensis. However, two or three transverse banding appeared at the anterior region of the acrosomal vesicle in C. gigas (Kim et al., 2010; Kang et al., 2012). In addition, Healy \& Lester (1991) reported that three to four horizontal bandings appeared at the anterior region of the acrosomal vesicle in $S$. commecials as a feature of the genus Saccostrea.

Hodgson \& Bernard (1986) and Healy (1989) stated that different subclasses of bivalves each have unique acrosomal morphologies, and the number of mitochondria in the sperm midpiece tends to be stale within any family or superfamily varying from a maximum of 14 in the mytilord Modiolus difficilis (Drozdov \& Reunov, 1986) to a minimum of 4 (common to many bivalve families) (Healy, 1989, 1995).

In this study, the number of mitochondria at the midpiece of the spermatozoon are four, and satellite fibres are found, as seen in C. gigas (Kim et al., 2010) and in $C$. nipponica (Kim, 2001). Judging from the resuts on the ultrastructure of mature spermatozoon, it is supposed that this species belongs to family Ostreidae in the subclass Pteriomorphia because the spermatozoon of this specis has special structural charateristics of the acrosomal vesicle containing an axial rod appeared between the acrosomal vesicle and the anterior nucleus fossa, and satellite fibres near the distal centriole and spherical mitochondria.

\section{ACKNOWLEDGEMENTS}

The authors are grateful to Dr. Hee Woong Gang, West Sea Fisheries Research Institute, for helpful comments on the manuscript. This research was supported in part by the funds (2007) from the Research Projects of Korea Ocean \& Fisheries Institute, Busan, Korea.

\section{REFERENCES}

Bernard RTF, Hodgson AN (1985) The fine structure of the sperm and spermatid differentiation in the brown mussel Perna perna. South Africa J Zool 20:5-9.

Daniels EW, Longwel AC, McNiff JM, Wolfgang RW (1971) A reinvestigation of the ultrastructure of the spermatozoa from the American oyster Crassostrea virginica. Trans American Micro Soc 90:275-282.

Drozdov TA, Reunov AA (1986) Spermatogenesis and the sperm ultrastructure in the mussel Modiolus difficillis. Tsitologiia 28:1069-1074.

Eckelbarger KJ, Davis CV (1996) Ultrastructure of the gonad and gametogenesis in the eastern oyster, Crassostrea virginica. II. Testis and spermatogenesis. Mar Biol 127: 89-96.

Franźen Å (1956) On spermatogenesis. Morphology of the spermatozoon, and biology of fertilization among invertebrates. Zool Bidr Uppsala 31:355-482.

Galtsoff FS, Phillpott DE (1960) Ultrastructure of the spermatozoon of the oyster, Crassostrea virginica. J Ultra Res 3:241-253.

Healy JM (1983) Ultrastructure of euspermatozoa of cerithiacean gastropods (Prosobranchia: Mesogastropoda). J Morp 178:57-75.

Healy JM (1988) Sperm morphology and its systematic importanc in the Gastropoda. In: Ponder WF. (ed) Prosobranch Phylogeny. Malacol Rev 4:251-266.

Healy JM (1989) Spermiogenesis and spermatozoa in the relict bivalve genus Neotrigonia: relevance to trigonioid relationships, particularly Unionoidea. Mar Biol 103: 75-85.

Healy JM, Lester RJG (1991) Spermultrastructure in the Australian oyster Saccostrea commercialis (Iredale \& Roughey) (Bivalvia: Ostreoidea). J Moll Stu 57:219224

Healy JM (1995) Sperm ultrastructure in the marine bivalve families Carditidae and Crassatellidae and its 
bearing on unification of the Crasssatelloidea with the Carditoidea. Zool Sci 24:21-28.

Healy JM (1996) Molluscan sperm ultrastructure: correlation with taxonomic units within the Gastropoda, Cephalopoda and Bivalvia. In: Taylor J (ed) Origin and Evolutionary Radiation of the Mollusca. Oxford University Press, London p. 99-113.

Hodgson AN, Bernard RTF (1986) Ultrastructure of the sperm and spermatogenesis of three species of Mytilidae (Mollusca, Bivalvia). Gamete Res 15:123-135.

Jamieson BGM (1987) The Ultrastructure and Phylogeny of Insect Spermatozoa. Cambridge University Press, Cambridge. pp. 137-172.

Jamieson BGM (1991) Fish Evolution and Systematics: Evidence from Spermatozoa. Cambridge University Press, Cambridge. pp. 181-194.

Kang HW, Chung EY, Kim JH, Chung JS, Lee KY (2012) Germ cell differentiations during spermatogenesis and taxonomic values of mature sperm morphology of Atrina (Servatrina) pectinata (Bivalvia, Pteriomorphia, Pinnidae). Dev Reprod 16:19-29.
Kim JH (2001) Spermatogenesis and comparative ultrastructure of spermatozoa in several species of Korean economic bivalves (13 families, 34 species). $\mathrm{Ph}$. D. thesis, Pukyung National University, $161 \mathrm{pp}$.

Kim JH, Chung EY, Choi KH, Lee KY, Choi MS (2010) Ultrastructure of the testis and germ cell development during spermatogenesis in male Crassostrea gigas (Bivalvia: Ostreidae) in western Korea. Kor J Malacol 26:235-244.

Osanai K, Kyozuka K (1982) Cross fertilization between sea urchin eggs and oyster spermatozoa. Gamete Res 5: 49-60.

Popham JD (1974) Comparative morphometrics of the acrosomes of the sperms of externally and internally fertilizing sperms of the sperms of the shipworms (Teredinidae, Bivalvia, Mollusca). Cell Tissue Res 150: 291-297.

Popham JD (1979) Comparative spermatozoon morphology and bivalve phylogeny. Malacol Rev 12:1-20.

Sousa M, Oliveria E (1994) An ultrastructural study of Crassostrea angulata (Mollusca, Bivalvia) spermatogenesis. Mar Biol 120:41-47. 